\title{
RANCANG BANGUN ROBOT FORKLIFT DENGAN KENDALI SMARTPHONE ANDROID BERBASIS ARDUINO MEGA 2560
}

\author{
Aan Marianto, Muchlas \\ Program Studi Teknik Elektro, Fakultas Teknologi Industri, Universitas Ahmad Dahlan \\ Kampus III, JIn. Prof. Dr. Soepomo,S.H. Umbulharjo, Yogyakarta 55161 \\ e-mail: aanmarianto@gmail.com, muchlas.te@uad.ac.id
}

\begin{abstract}
The use of robots is very important in improving the production process of an industry, Automation is one of the realization of technological developments, through the time required for the production process is shorter so that the productivity increases. Currently smartphone technology that can be used for various application has been developed. The use of smartphones as controlling units will provide a high level of practicality, considering that these devices are easy to use and have become a part of the everyday item that is always carried by humans. Through this research a fork lift robot that can be controlled through Android smartphone will built. The results show that the robot can be controlled via android smartphone to move several item with an average yield of 31.2 seconds/phase moving goods, the load which can be lifted is 200 grams. The limitation of torque and mechanical system used is still becoming a constraint that has to be fixed.
\end{abstract}

Keywords: microcontroller arduino mega 2560; forklift robot; android; bluetooth HC 05

\begin{abstract}
Abstrak
Penggunaan robot dirasakan sangat penting dalam meningkatkan proses produksi suatu industry, otomatisasi merupakan salah satu realisasi dari perkembangan teknologi, melalui otomatisasi waktu yang diperlukan untuk proses produksi juga semakin singkat sehingga produktivitas meningkat. Saat ini telah berkembang teknologi smartphone yang dapat digunakan untuk berbagai aplikasi. Penggunaan smartphone sebagai unit pengendali akan memberikan tingkat kepraktisan yang tinggi, mengingat piranti ini mudah digunakan dan telah menjadi bagian dari perlengkapan yang sehari-hari selalu dibawa oleh manusia. Melalui penelitian akan dibangun robot fork lift yang dapat dikendalikan melalui smartphone Android. Hasil penelitian menunjukkan bahwa robot dapat dikendalikan melalui smartphone Android untuk memindahkan barang dengan hasil rata-rata 31,2 detik perfase menindahan barang, beban masimal yang dapat diangkat 200 gram. Keterbatasan torsi dan sistem mekanik yang digunakan masih menjadi kendala yang harus diperbaiki.
\end{abstract}

Kata Kunci: mikrokontroller arduino mega 2560; robot forklift; android; bluetooth HC 05

\section{Pendahuluan}

Otomatisasi merupakan salah satu realisasi dari perkembangan teknologi, melalui otomatisasi waktu yang diperlukan untuk proses produksi juga semakin singkat sehingga produktivitas meningkat. Selain jumlah produksi lebih banyak, biaya pengoperasiannya juga dapat ditekan seminimal mungkin serta membutuhkan tenaga yang lebih sedikit,. Untuk sekarang ini sistem forklift banyak digunakan untuk memindahkan barang hasil produksi untuk disimpan digudang maupun untuk memindahkan bahan baku dari gudang untuk diproduksi sehingga dalam pemindahan barang tersebut dapat berjalan secara cepat dan efisien dibandingkan dengan menggunakan tenaga manusia yang memakan banyak waktu [1-3].

Saat ini telah berkembang pula teknologi smartphone yang dapat digunakan untuk berbagai aplikasi. Penggunaan smartphone sebagai unit pengendali akan memberikan tingkat kepraktisan yang tinggi,mengingat piranti ini mudah digunakan dan telah menjadi bagian dari perlengkapan yang sehari-hari selalu dibawa oleh manusia [4-6].

Berdasarkan pertimbangan diatas, melalui penelitian ini akan dirancang sebuah sistem kontrol gabungan antara smartphone Android dan mikrokontroler untuk mengendalikan robot fork lift yang dapat digunakan untuk memindahkan barang [7]. 


\section{Metode Penelitian}

Penelitian dilakukan untuk merancang dan membuat sebuah prototipe forklift robot menggunakan motor DC sebagai penggerak, module bluetooth, mikrokontroler yang dapat dikendalikan dengan smartphone Android menggunakan komunikasi bluetooth.

Agar mempermudah dalam melakukan pembahasan dan pembaca dalam memahami kinerja rancangan alat, maka dapat dilihat pada Gambar 1.

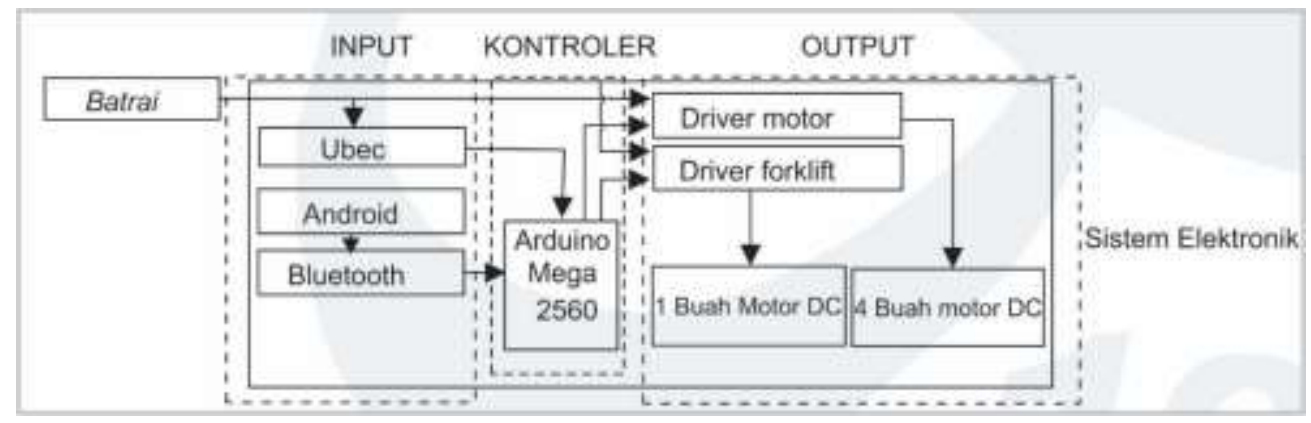

\subsection{MIT App Inventor}

Gambar 1. Diagram blok perancangan

MIT App Inventor adalah aplikasi inovatif yang dikembangan Google dan MIT untuk mengenalkan dan mengembangkan pemrograman Android dengan mentrasformasikan bahasa pemrograman yang kompleks berbasis teks menjadi berbasis visual (drag and drop) berbentuk blok-blok digunakan untuk membuat aplikasi pengontrol pada penelitian ini.

\subsection{Module Bluetooth $\mathrm{HCO5}$}

HC-05 Bluetooth Module merupakan modul komunikasi nirkabel pada frekuensi $2.4 \mathrm{GHz}$ dengan pilihan koneksi slave, ataupun master. Sangat mudah digunakan dengan mikrokontroler untuk membuat aplikasi wireless. Interface yang digunakan adalah serial $R X D, T X D, V C C$ dan GND. Built in LED sebagai indikator koneksi bluetooth. Tegangan input antara $3.6 \sim 6 \mathrm{~V}$. Arus saat unpaired sekitar $30 \mathrm{~mA}$, dan saat paired (terhubung) sebesar 10mA. 4 pin interface 3.3V dapat langsung dihubungkan ke berbagai macam mikrokontroler (khusus Arduino, 8051, 8535, AVR, PIC, ARM, MSP430, etc.). Jarak efektif jangkauan sebesar 10 meter.

\subsection{Catu Daya}

Catu daya yang digunakan baterai lippo 3 sel bertegangan $12 \mathrm{~V}$, sebagai sumber tegangan untuk menghidupkan mikrokontroler dan motor driver.

\subsection{Motor DC}

Motor DC dengan gearbox yaitu motor DC yang telah dilengkapi dengan sejumlah gear, sehingga menghasilkan putaran yang stabil dan memiliki torsi yang besar. Motor gear ini memiliki tegangan input sebesar 12V DC, 250rpm, torsi 3,8kg, berat motor $80 \mathrm{gram}$, Arus $1200 \mathrm{~mA}$, diameter $25 \mathrm{~mm}$. Motor DC ini digunakan untuk keperluan torsi yang tinggi.

\subsection{Motor Driver H-Bridge}

Untuk menggerakkan motor DC dibutuhkan suatu rangkaian penggerak. Rangkaian penggerak disini dibangun dari transistor yang dirangkai sebagai saklar elektronik. Transistor adalah salah satu komponen yang dapat digunakan sebagai saklar elektronik. Pada penelitian ini digunakan untuk menggerakan 5 buah motor DC.

\subsection{Arduino IDE}

Arduino sketh IDE atau Arduino Development Environment terdiri dari editor teks untuk menulis kode, sebuah area pesan, sebuah konsol, sebuah toolbar dengan tomol-tombol untuk fungsi yang umum dan beberapa menu. Arduino Development Environment terhubung ke arduino board untuk upload program dan juga untuk berkomunikasi dengan arduino board. 


\subsection{Arduino Mega 2560}

Arduino Mega 2560 adalah papan pengembangan mikrokontroler yang berbasis Arduino dengan menggunakan chip ATmega2560. Board ini memiliki pin $1 / O$ yang cukup banyak, sejumlah 54 buah digital I/O pin (15 pin diantaranya adalah PWM (pulse width modulation)), 16 pin analog input, 4 pin UART (serial port hardware). Pada penelitian ini pin 0 dan 1 digunakan sebagai komunikasi $r x$ tx dengan module bluetooth, pin PWM 2 sampai dengan 11 digunakan sebagai keluaran.

\subsection{Diagram Alir Sistem}

Diagram secara keseluruhan dapat dijelaskan pada Gambar 2.

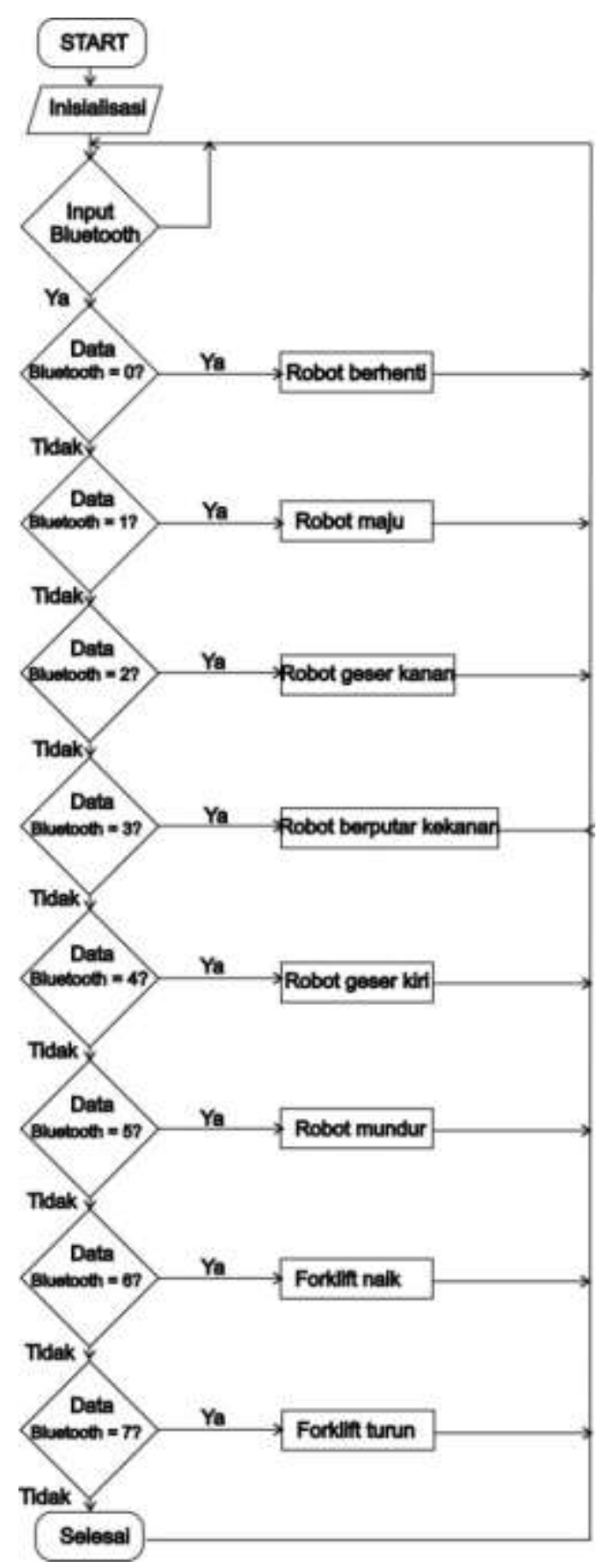

Gambar 2. Diagram alir robot fork lift 
Penjelasan Diagram alir pada Gambar 2.

1. Langkah pertama adalah menginisialisasi data masukan dari bluetooth.

2. Kemudian menunggu penerima data dari koneksi Android data bluetooth bernilai sama dengan 0 robot berhenti.

3. Data bluetooth bernilai sama dengan 1 maka robot bergerak maju.

4. Data bluetooth bernilai sama dengan 2 maka robot bergerak kekanan.

5. Data bluetooth bernilai sama dengan 3 maka robot berputar kekanan.

6. Data bluetooth bernilai sama dengan 4 maka robot bergerak kekiri.

7. Data bluetooth bernilai sama dengan 5 maka robot bergerak mundur.

8. Data bluetooth bernilai sama dengan 4 maka sistem fork lift bergerak naik.

9. Data bluetooth bernilai sama dengan 7 maka sistem bergerak fork lift turun.

10. Proses akhir adalah menggulang program dari awal atau selesai.

\subsection{Skema Rangkaian Keseluruhan}

Rancang bangun robot forklift dengan kendali smartphone Android berbasis Arduino Mega 2560 dapat dilihat pada Gambar 4.

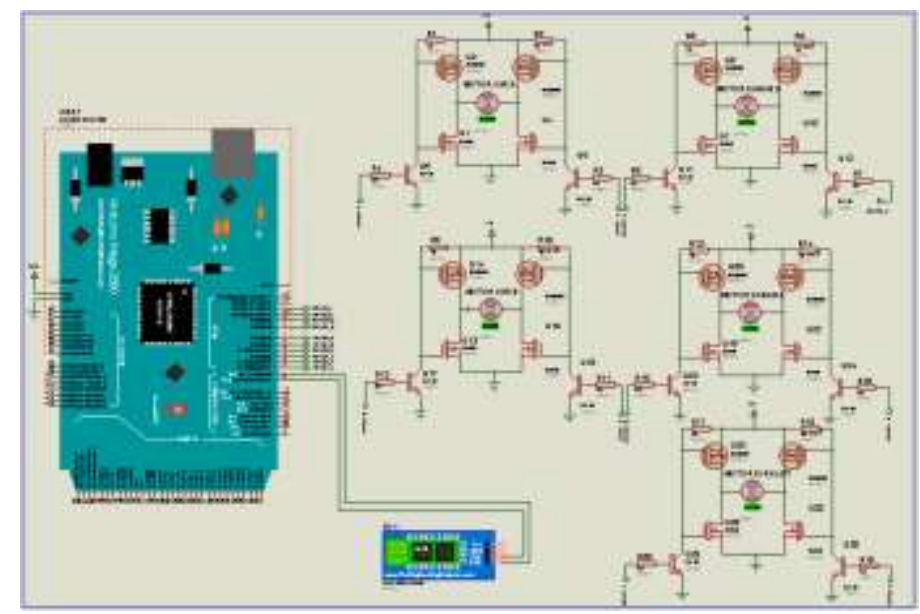

Gambar 4. Rangkaian sistem keseluruhan

Gambar 4 rangkaian diatas menunjukkan sistem secara keseluruhan yang mana terdiri dari arduino mega 2560 yang terhubung pin $r x$ dan $t x$ pada module bluetooth sebagai input. Sedangkan output pin PWM 2 sampai 11 digunakan untuk mengontrol motor driver.

\subsection{Tampilan Interface}

pada layar Android berupa tombol-tombol untuk menggontrol robot forflift dengan fungsi kegunaan berbeda-beda berikut tampilan interface Android pada Gambar 5.

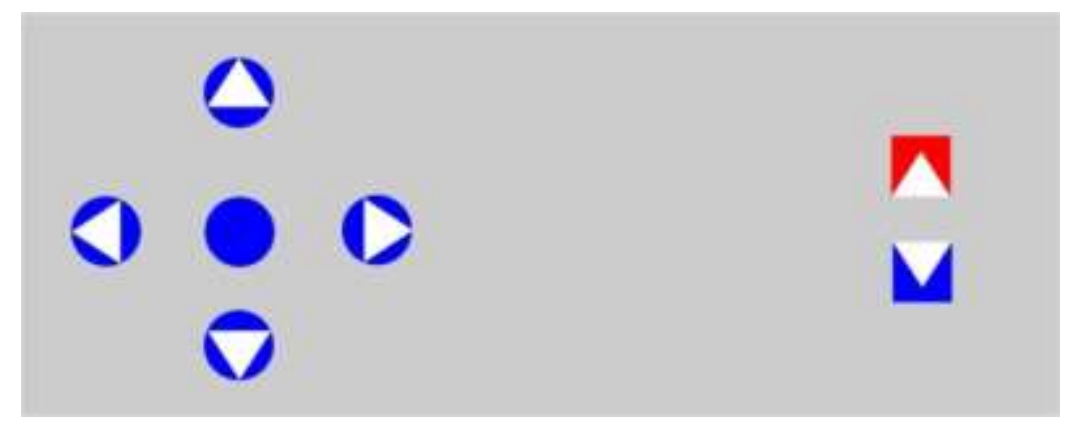

Gambar 5. Tampilan android interface 
Keterangan simbol:

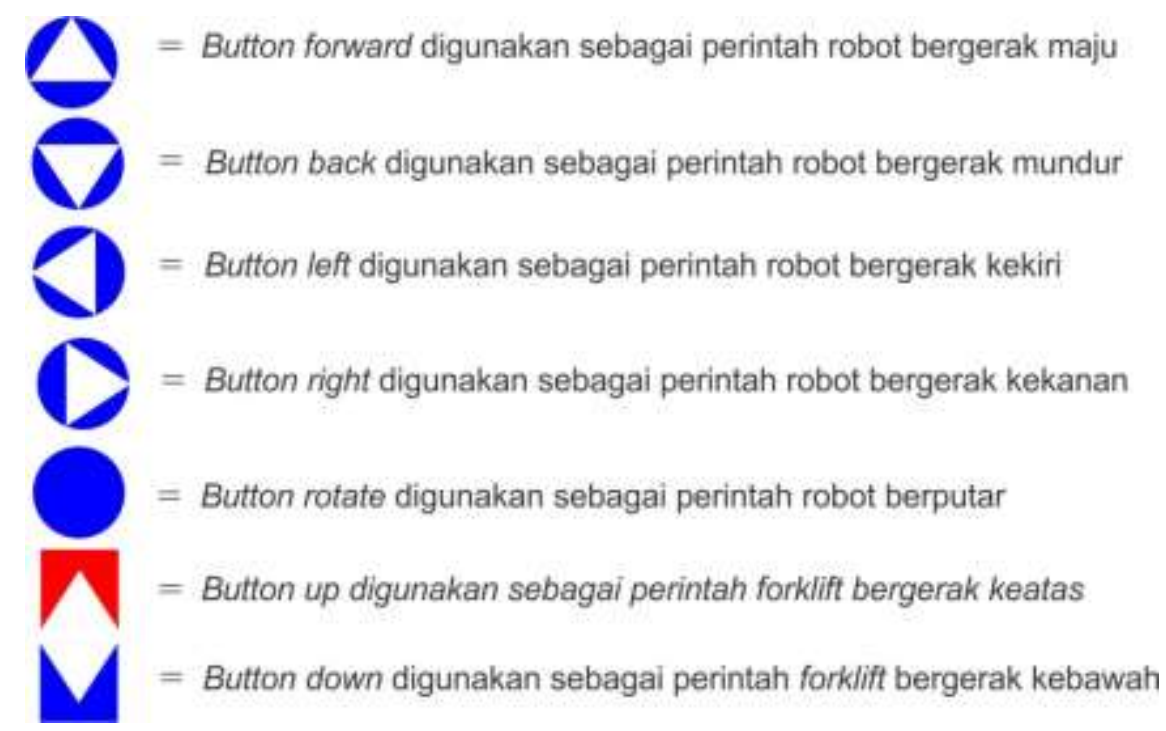

Program dimulai dari pembacaan variabel. Variabel ini terdiri dari label-label atau register yang berfungsi sebagai pengganti register yang ada di mikrokontroler. Pembacaan data Android dimulai dengan menginisialisasi data yang masuk pada pin 0 dan 1. Selanjutnya program akan memberikan data antara 0-7 dari Android. Setiap data yang dimasukan ke mikrokontroler yang akan diseleksi tiap tombol yang digunakan. Apabila ada data antara 0-7 yang sesuai dengan data tombol Android maka interuksi selanjutnya menjalankan eksekusi program. Jika tidak ada data antara 0 sampai 7 yang sesuai dengan data tombol Android, maka program akan menunggu sampai adanya penekanan tombol selanjutnya yang memiliki kesesuaian data 0 sampai 7 data tombol Android. Mikrokontroler akan memberikan pulsa pemicu pada setiap motor driver. Pulsa pemicu ini akan mensaklar transistor untuk memutar motor DC. Setiap driver diberi pulsa pemicu berbeda-beda sesuai dengan motor DC yang akan digerakkan.

\section{Hasil Pengujian}

\subsection{Pengujian Motor driver DC}

Tebel 1. Hasil pengujian motor driver DC

\begin{tabular}{llllll}
\hline No & Motor 1 & Motor 2 & Motor 3 & Motor 4 & Pergerakan robot \\
\hline 1 & A $(200)$ & B $(-200)$ & B $(-200)$ & A $(200)$ & Maju \\
2 & B $(-200)$ & A (200) & B $(-200)$ & A (200) & Mundur \\
3 & A (200) & A $(200)$ & A $(200)$ & A $(200)$ & Belok Kanan \\
4 & B (-200) & B $(-200)$ & B $(-200)$ & B $(-200)$ & Belok Kiri \\
5 & B $(-200)$ & B $(-200)$ & A (200) & A (200) & Berputar Kekiri \\
\hline
\end{tabular}

Keterangan:

$A=$ Searah jarum jam

$\mathrm{B}=$ Berlawanan arah jarum jam

Data pada Tabel 1 pengujian motor driver DC adalah robot akan bergerak maju apabila motor 1 berputar searah jarum jam, motor 2 berputar berlawanan arah jarum jam, motor 3 berputar berlawanan arah jarum jam, motor 4 berputar searah jarum jam dengan kecepatan PWM yang sama. Pengujian dilakukan untuk menginginkan pergerakan robot sesuai rancangan.

\subsection{Pengujian Sistem Forklift}

Pengujian sistem fork lift dilakukan untuk mengetahui seberapa besar kinerja angkatan beban yang dapat diangkut pada sistem forklift robot, dapat dilihat pada Tabel 2. 
Tabel 2. Pengujian sistem fork lift

\begin{tabular}{ccccccc}
\hline No & \multicolumn{5}{c}{ Jumlah Beban(gram) } & Keterangan \\
\cline { 2 - 5 } & 100 & 200 & 300 & 400 & 500 & \\
\hline 1 & $\mathrm{O}$ & $\mathrm{O}$ & $\mathrm{X}$ & $\mathrm{X}$ & $\mathrm{X}$ & O = Berhasil \\
2 & $\mathrm{O}$ & $\mathrm{O}$ & $\mathrm{X}$ & $\mathrm{X}$ & $\mathrm{X}$ & \\
3 & $\mathrm{O}$ & $\mathrm{O}$ & $\mathrm{X}$ & $\mathrm{X}$ & $\mathrm{X}$ & $\mathrm{X}=$ Gagal \\
4 & $\mathrm{O}$ & $\mathrm{O}$ & $\mathrm{X}$ & $\mathrm{X}$ & $\mathrm{X}$ & \\
5 & $\mathrm{O}$ & $\mathrm{O}$ & $\mathrm{X}$ & $\mathrm{X}$ & $\mathrm{X}$ & \\
\hline
\end{tabular}

Hasil dari pengujian forklift robot diperoleh beban maksimal yang dapat diangkat robot sebanyak 200gram. Pengujian pada angkatan 300-500gram mengalami kegagalan dikarenakan sistem forklift tidak mampu menggangkat beban.

\subsection{Pengijian Koneksi Android}

Pengujian sistem Android dilakukan untuk mengetahui kinerja sistem Android yang digunakan untuk mengontrol robot. Pengujian dilakukan dengan mengkoneksikan sistem Android dengan robot dan mengontrol robot dengan jarak antara 1 sampai 40 meter. Hasil yang diperoleh dari pengujian sistem Android ditunjukkan pada Tabel 3 berikut.

Tabel 3. Hasil pengujian jarak koneksi bluetooth

\begin{tabular}{|c|c|c|c|c|c|c|}
\hline \multirow[t]{2}{*}{ No } & \multicolumn{5}{|c|}{ Jarak (meter) } & \multirow[t]{2}{*}{ Keterangan } \\
\hline & 10 & 20 & 30 & 35 & 40 & \\
\hline 1 & $\mathrm{O}$ & $\mathrm{O}$ & $\mathrm{O}$ & $\mathrm{O}$ & $\mathrm{X}$ & $\mathrm{O}=$ Berhasil \\
\hline 2 & 0 & $\mathrm{O}$ & 0 & 0 & $x$ & $X=$ Gagal \\
\hline 3 & $\mathrm{O}$ & $\mathrm{O}$ & $\mathrm{O}$ & $\mathrm{O}$ & $\mathrm{X}$ & \\
\hline 4 & 0 & 0 & 0 & 0 & $\mathrm{X}$ & \\
\hline 5 & 0 & $\mathrm{O}$ & $\mathrm{O}$ & 0 & $\mathrm{X}$ & \\
\hline
\end{tabular}

Hasil pengujian ini diperoleh informasi bahwa jarak efektif yang bisa dijangkau koneksi bluetooth antara 1-10 meter walaupun pada pengujian jarak maksimal yang dapat dijangkau bluetooth pada 35 meter robot masih dapat dikendalikan, pengujian pada jarak lebih dari 40 meter mengalami kegagalan karena koneksi bluetooth terputus.

\subsection{Pengujian Sistem Secara Keseluruhan}

Setelah dilakukan pengujian perbagian sesuai yang rancangan, maka langkah selanjutnya dilakukan pengujian sistem secara keseluruhan untuk mengetahui kinerja dari robot. Pengujian secara keseluruhan dilakukan dengan cara menggabungkan keseluruhan sistem rangkaian (hardware), mekanik, dan perangkat lunak (software).

Pengujian dilakukan dengan memberikan sumber tegangan DC 12 volt kepada sistem mikrokontroler dan motor driver DC guna menyalakan sistem mikrokontroler serta motor driver DC. Langkah berikutnya adalah menghubungkan sistem Android dengan bluetooth module pada robot. Robot ditempatkan pada bidang A pada posisi start kendalikan menuju bidang B untuk menggambil muatan pertama berisikan 1 muatan dengan berat 100 gram tiap muatan untuk dipindahkan ke bidang $\mathrm{C}$ dari hasil percobaan pengujian jumlah beban robot hanya dapat membawa maksimal muatan sebanyak 200gram ditunjukkan pada Tabel 4 berikut.

Tabel 4. Hasil pengujian kekuatan forklift robot

\begin{tabular}{|c|c|c|c|c|c|c|}
\hline \multirow[t]{2}{*}{ No } & \multicolumn{5}{|c|}{ Jumlah muatan (ons) } & \multirow[t]{2}{*}{ Keterangan } \\
\hline & 1 & 2 & 3 & 4 & 5 & \\
\hline 1 & $\mathrm{O}$ & $\mathrm{O}$ & $\bar{X}$ & $\mathrm{X}$ & $\bar{X}$ & Beban Robot $=3124$ gram \\
\hline 2 & $\mathrm{O}$ & $\mathrm{O}$ & $\mathrm{X}$ & $\mathrm{X}$ & $\mathrm{X}$ & \\
\hline 3 & $\mathrm{O}$ & $\mathrm{O}$ & $\mathrm{X}$ & $\mathrm{X}$ & $\mathrm{x}$ & $\mathrm{O}=$ Berhasil \\
\hline 4 & $\mathrm{O}$ & $\mathrm{O}$ & $\mathrm{X}$ & $\mathrm{X}$ & $\mathrm{X}$ & $X=$ Gagal \\
\hline 5 & $\mathrm{O}$ & $\mathrm{O}$ & $\mathrm{X}$ & $\mathrm{x}$ & $\mathrm{X}$ & \\
\hline
\end{tabular}


Untuk hasil uji coba sebanyak 5 kali pengukuran didapat bahwa robot berhasil memindahkan jumlah beban angkatan 1 sampai 2 pengujian pada angkatan beban sebanyak 3 dan 4 terjadi kegagalan dikarenakan sistem forklift tidak dapat menahan beban angkatan yang besar akibatnya sistem fork lift tidak mau menaikan angkatan secara sempurna.

Pengujian selanjutnya adalah menjalankan robot sebanyak 5 kali dengan beban muatan sebanyak 2 untuk mendapatkan perbandingan rata-rata waktu pergerakan robot dalam memindahkan barang dari satu kali fase pemindahan ditunjukkan pada Tabel 5.

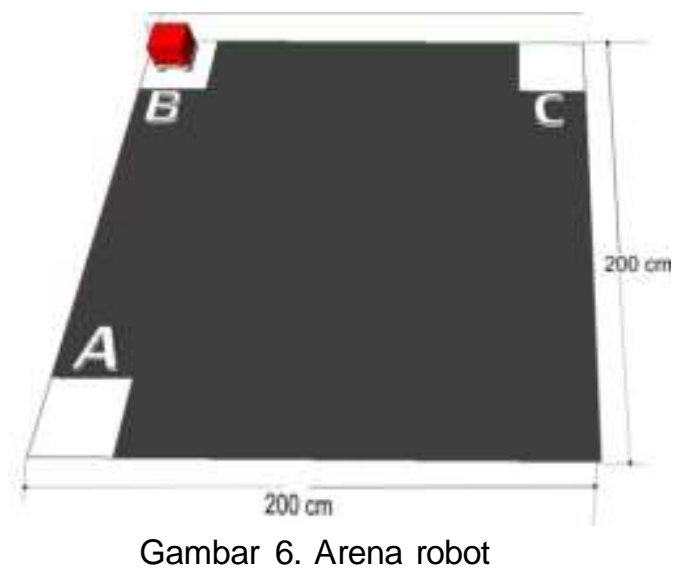

Arena robot berupa lintasan yang berbentuk persegi 4 dengan 3 buah bidang $A$, $B$, dan $C$ dengan jarak antar bidang sepanjang $200 \mathrm{~cm}$. Jadi total jarak didapat dari penjumlahan jarak $A B$ $200 \mathrm{~cm}$ ditambah jarak BC $200 \mathrm{~cm}$ sama dengan $400 \mathrm{~cm}$.

Tabel 5. Hasil pengujian waktu tempuh robot

\begin{tabular}{cccc}
\hline No & Jumlah Muatan & Waktu(s) & Jarak $(\mathrm{cm})$ \\
\hline 1 & 2 & 33 & 400 \\
2 & 2 & 30 & 400 \\
3 & 2 & 25 & 400 \\
4 & 2 & 36 & 400 \\
5 & 2 & 32 & 400 \\
\hline
\end{tabular}

Kecepatan pergerakan robot diperoleh dengan menghitung perbandingan antara waktu tempuh dibagi jarak. Diketahui dari pengujian sebelumnya pada Tabel 5 sehingga kecepatan pergerakan robot dapat diperoleh dengan persamaan berikut.

$$
\mathrm{v}=\mathrm{s} / \mathrm{t}
$$

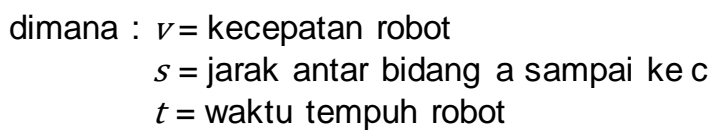

Hasil pengujian kecepatan robot dapat dihitung menggunakan persamaan (1) dan hasilnya ditunjukkan pada Tabel 6.

Tabel 6. Hasil pengujian kecepatan robot

\begin{tabular}{cccc}
\hline No & $\begin{array}{c}\text { Jarak } \\
(\mathrm{cm})\end{array}$ & Waktu (detik) & Kecepatan(cm/detik) \\
\hline 1 & 400 & 33 & 12,12 \\
2 & 400 & 30 & 13,33 \\
3 & 400 & 25 & 16 \\
4 & 400 & 36 & 11,11 \\
5 & 400 & 32 & 12,5 \\
\hline
\end{tabular}


Hasil percobaan sebanyak 5 kali pengukuran waktu pergerakan robot didapat waktu ratarata pergerakan robot 31,2 detik per fase pemindahan.

\section{Kesimpulan}

Dari hasil uji coba dan analisa yang telah dilakukan dapat diambil kesimpulan telah berhasil dibuat prototipe robot forklift dengan kendali smartphone Android berbasis Arduino Mega 2560 digunakan untuk memindahkan barang sesuai rancangan. Spesifikasi robot memiliki 4 buah roda, 4 buah motor DC, berdimensi $25 \times 25 \mathrm{~cm}$ dengan tinggi $58 \mathrm{~cm}$, sistem fork lift, dikendalikan dengan smartphone dan mempunyai berat kosong 3124 gram. Catu daya yang digunakan adalah baterai Lippo 12 volt. Setelah dilakukan percobaan disimpulkan robot dapat bekerja secara baik dengan maksimal beban angkatan 200 gram, dengan rata-rata waktu pemindahan satu kali fase 31,2 detik.

\section{Referensi}

[1] Rahmiyati, P., Firdau, G., Fathorrahman, N., 2014, Implementasi Sistem Bluetooth Menggunakan Android dan Arduino untuk Kendali Peralatan Elektronik, Jurnal ELKOMIKA, No.1, Vol. 2, Hal 1-14.

[2] D.Samsi (2008). Pengembangan Sistem Pneumatic Dalam Bidang Robotic Dalam Kaitanya Dengan Otomasi Proses Industri, Jurnal Teknoin.

[3] Dwi, Taufik (2010). Buku Pintar ROBOTIKA. Yogyakarta: Andi

[4] Istiyanto, A. J. (2014). Pengantar Elektronika \& Instrumentasi Pendekatan Project Arduino \& Android. Yogyakarta: Andi.

[5] Tani, R. (2012). Perancangan Antar muka IP-Cam Wifi Robot. Jurnal Teknik Elektro Dan Komputer Universitas Sam Ratulangi Manado, 1, 3-4.

[6] Potts, J., dan Sukittanon, S. (2012). : Exploiting Bluetooth on Android Mobile Devices for Home Security Application. Proceedings of IEEE, University of Tennessee at Martin, USA

[7] Masinambow, V., Najoan, M.E.I, Lumenta, A.S.M., 2014, Pengendali Saklar Listrik Melalui Ponsel Pintar Android.

[8] Sunomo (1996),Elektronikall.Yogyakarta:IKIP Yogyakarta.

[9] Sumarna. (2006). Elektronika digital. Yogyakarta: Graha ilmu.

[10] Syahwil, M. (2013). Panduan Mudah Simulasi dan Praktek Mikrokontroler Arduino. Yogyakarta: Andi.

[11] Dinata, M, Y. (2014). Arduino itu Mudah. Jakarta: Gramedia. 